\title{
Maintaining (not just achieving) optimal patient outcomes
}

\author{
Tom C. Nguyen, MD
}

\author{
From the University of Texas Houston-Memorial Hermann, Houston, Tex. \\ Disclosures: Author has nothing to disclose with regard to commercial support. \\ Received for publication Nov 17, 2015; accepted for publication Nov 19, 2015; available ahead of print Dec 17, \\ 2015. \\ Address for reprints: Tom C. Nguyen, MD, University of Texas Houston-Memorial Hermann, Houston, TX \\ (E-mail: tom.c.nguyen@gmail.com). \\ J Thorac Cardiovasc Surg 2016;151:655-6 \\ $0022-5223 / \$ 36.00$ \\ Copyright (C 2016 by The American Association for Thoracic Surgery \\ http://dx.doi.org/10.1016/j.jtcvs.2015.11.034
}

\section{...the most difficult thing about surgery-even heart \\ surgery-is getting a chance to do it.}

This quotation, from the Presidential Address ${ }^{1}$ by Norman Shumway, MD, at the 67th Annual Meeting of The American Association for Thoracic Surgery, summarizes the paradox that we face as we look toward the future of cardiac surgery. The hardest thing about heart surgery is finding the chance to do it. Yet, how do we train future surgeons to perform complex surgery while still achieving optimal patient outcomes?

Coronary artery bypass grafting (CABG) surgery is the most commonly performed cardiac surgical procedure. ${ }^{2}$ Despite a more intense focus on patient safety and optimal outcomes in recent years, mortality rates have remained stable, despite increasing case complexity. ${ }^{3}$ However, this focus has resulted in fewer opportunities for surgical trainees to learn complex surgical procedures through direct experience. Outcomes after CABG are placed under an unfiltered magnifying glass, and surgeons may be reluctant to incorporate trainee involvement. As time goes on, who will perform these surgeries while maintaining optimal patient outcomes?

The meta-analysis by Virk and colleagues ${ }^{4}$ suggests that trainee-performed CABG does not adversely affect postoperative outcomes and survival, which ultimately affect surgical training. The meta-analysis, which included 16 observational studies and almost 53,000 subjects, aimed to assess the impact of trainee operator status on clinical outcomes after CABG surgery. Increased aortic crossclamp and cardiopulmonary bypass duration was associated with trainee cases. However, perioperative mortality was similar for both trainee- and consultant-performed $\mathrm{CABG}$, and no significant difference was found in incidence of perioperative stroke, myocardial infarction, acute renal failure, reoperation for bleeding, or wound infection. Trainee operator status was not associated with increased midterm mortality. A subgroup analysis ( 5 studies and 8025 subjects) demonstrated that off-pump CABG trainee cases were not associated with increased perioperative mortality or morbidity.

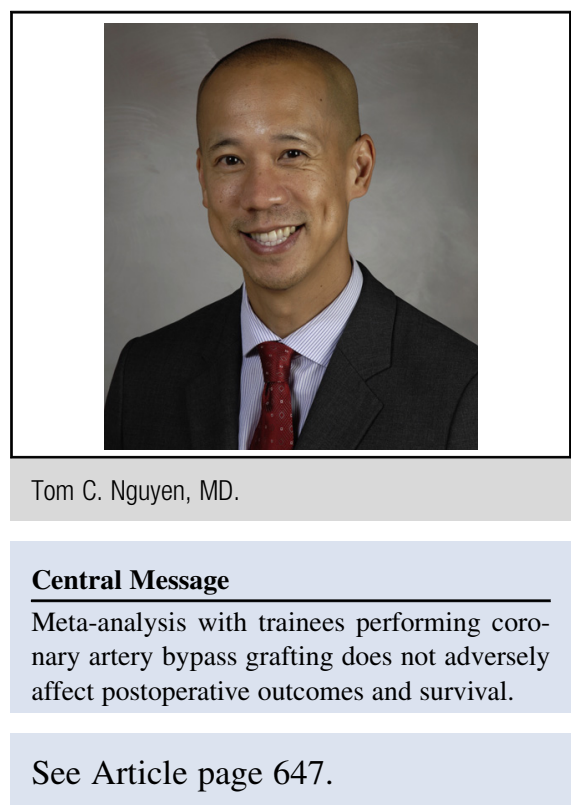

Virk and colleagues ${ }^{4}$ should be commended for their systematic, thoughtful, and timely study. They have investigated the literature with a focus on a critical question, with important clinical implications for surgeons, trainees, insurers, and patients. This analysis included data from many studies and subjects. In addition, the well conducted meta-analysis design can be a powerful tool to summarize individual studies and address questions.

The authors did a thorough job of pointing out potential limitations to their analysis. The subgroup analysis focusing on off-pump CABG was conducted for only 5 studies, most from centers with high volumes of off-pump CABG procedures; therefore, the results may have limited generalizability to most other cardiac surgeons. Even with experienced surgeons, off-pump CABG has been associated with reduced long-term graft patency. ${ }^{5}$ Moreover, the meta-analysis was not specifically designed to look at trainee outcomes after off-pump $\mathrm{CABG}$, and conclusions about differences between on-pump and off-pump CABG should be made with caution.

In addition, the paucity of data on long-term graft patency is a limitation. Considering all factors, the most important one after CABG is graft patency. The authors note that it was not possible to report on outcomes such as angiographic measurements, freedom from revascularization, and recurrence of angina. Other limitations include potential differences in the definition of trainee and variations in trainee or consultant experience. Most of the included studies were based in Europe, which may limit 
the generalizability of the results for US-based practices. Variation in surgeon experience, despite the "trainee" or "consultant" label, may be a limiting factor.

In conclusion, this well conducted meta-analysis suggests that trainee-performed CABG does not adversely affect postoperative outcomes and survival. Limitations, such as lack of long-term graft patency data, and of ability to draw conclusions for off-pump CABG, must be kept in mind. We must strive to create opportunities for trainees to learn the complex surgical techniques required for optimal outcomes from CABG. As Shumway ${ }^{1}$ duly noted: "Certainly it cannot matter as much who does the operation, as how it is done."

\section{References}

1. Shumway NE. Some thoughts from the other side of the table, or the last Presidential Address. J Thorac Cardiovasc Surg. 2011;142:1296-8.

2. Abu-Omar Y, Taggart DP. Coronary artery bypass surgery. Medicine. 2014;42: 527-31.

3. Grant SW, Hickey GL, Dimarakis I, Trivedi U, Bryan A, Treasure T, et al. How does EuroSCORE II perform in UK cardiac surgery: an analysis of 23,740 patients from the Society for Cardiothoracic Surgery in Great Britain and Ireland National Database. Heart. 2012;98:1568-72.

4. Virk SA, Bowman SRA, Chan L, Bannon PG, Ahmed WA, French BG, et al. Equivalent outcomes after coronary artery bypass graft surgery performed by consultant versus trainee surgeons: A systematic review and meta-analysis. J Thorac Cardiovasc Surg. 2016;151:647-54.

5. Shroyer AL, Grover FL, Hattler B, Collins JF, McDonald GO, Kozora E, et al; Veterans Affairs Randomized On/Off Bypass (ROOBY) Study Group. On-pump versus off-pump coronary-artery bypass surgery. $N$ Engl J Med. 2009;361: $1827-37$. 